regelbundet i februari och ökade sedan i antal till juni och juli. Nedgången under dessa månader hängde troligen samman med att adulta fåglar jagade närmare sina boplatser som inte låg inom vårt undersökningsområde. En senare topp noterades i augusti när årets ungfåglar blivit flygga. Antalet minskade till i november varefter rovfåglar inte sågs förrän följande januari.

Adulta ripor var utsatta för predationsrisk från fem rovfåglar: kungsörn, jaktfalk, duvhök, fjällvråk och blå kärrhök. Observationerna av fjällvråk under sommaren utgjorde $32 \%$ av alla rovfågelsobservationer. Ripornas ägg och kycklingar riskerade predation från fem andra fåglar: korp, kråka, skata, fiskmås och fjällabb. Fem små fågelpredatorer sågs också men de anses inte vara viktiga som rippredatorer: sparvhök, tornfalk, stenfalk, jorduggla och hökuggla.

Inga signifikanta skillnader i antal rovfågelobservationer noterades mellan ett område med och ett område utan jakt åren 1993 till 1995. Antalet observationer under dessa år gick ner men i ungefär samma omfattning i båda områdena.

Säsongstrenderna svarade ungefärligen mot snötäcke och bytestillgänglighet. De flesta rovfåglar fanns i området då bytestillgången var god under sommaren. Under vintern hindrade vädret och den låga bytestillgången rovfåglarna från att vistas i området även om nyligen dödade ripor visade att duvhök och jaktfalk fanns i december och januari. Augusti är troligen den månad då det största antalet ripor tas eftersom både rovfåglarnas och ripornas ungar då är flygga. Predationen kan dock ha större inverkan på ripstammen under andra delar av året då det finns färre ripor och färre alternativa byten.

A. Adam Smith, Edward Grey Institute, Dept. of Zoology, South Parks Road, Oxford OX1 3PS, UK

https://doi.org/10.34080/os.v6.22535

\section{Huskattens predation på fåglar i Sverige}

\section{SÖREN SVENSSON}

Katten betraktas allmänt som en svår predator på småvilt, inklusive fåglar. I tätorterna har man på många håll länge haft särskilda jägare som på kommunens vägnar skjuter eller fångar och avlivar katter (och andra s.k. skadedjur). Utanför tätorterna brukar jägare ofta också skjuta katter som påträffas utanför gårdar och trädgårdar. Det finns således en säregen kluvenhet i människans syn på katten. Å ena sidan är katten ett av våra vanligaste och mest omtyckta husdjur, å andra sidan bekämpas den. Katten är det enda husdjur som folk låter gå ut fritt i naturen, mer eller mindre medvetna om att den ägnar sig åt att jaga småfåglar och andra djur. När det gäller att släppa hunden lös har vi en helt annan syn. Säreget med människans kluvna inställning till katten är också, om än parentetiskt i detta sammanhang, hur bekymmerslöst folk låter sina katter exponeras för trafiken, som är en av de största dödsorsakerna bland huskatterna. Men båda fenomenen understryker kattens dubbla natur som både tam och vild, tam och tillgiven innanför men ett vilt djur utanför hemmets dörr.

Men hur mycket sanning finns egentligen i påståendet att katten skadar småviltstammarna och fågelbestånden? Till en del beror det naturligtvis på hur mycket en katt vistas utomhus. I detta avseende växlar det mycket, från rena inomhuskatter till förvildade katter som tillbringar nästan all tid ute och inte har någon fast anknytning till ett hushåll. Båda dessa extremer är dock sällsynta. Den typiska katten är knuten till ett eller flera hushåll, där den får mat och kanske också oftast tillbringar natten och perioder med dåligt väder, men vistas i övrigt mestadels utomhus.

När jag inför denna uppsats sökte i litteraturen efter uppgifter om kattens påverkan på sina bytesdjur, förbluffades jag av hur få uppgifter det finns, trots att litteraturen om katten är mycket omfattande. När det gäller kattens jakt börjar de flesta studier först när katten fångat sitt byte, d.v.s. studier av kattens beteende när den behandlar ett upptäckt byte. Denna brist på kunskap om kattens egentliga jaktbeteende ute i naturen noteras också av Turner \& Meister (1988). Fitzgerald (1988) har sammanfattat merparten av de tillgängliga studierna av kattens bytesval och effekter på bytespopulationer och kan vad gäller fåglar bara redovisa ett mycket magert resultat. De flesta studier rör de våldsamt destruktiva effekter som katter i likhet med andra inplanterade däggdjursarter haft på fågelbestånd på öar. Det är också signifikativt, och säkerligen en avspegling av kattforskarnas intresseinrikting, att det kattsymposium som hölls i påZoologiska institutionen i ZürichIrchel 1986 (Turner \& Bateson 1988) samlade forskare som såg tillvaron ur kattens (och människans) synpunkt, inte ur bytesdjurens.

Huskatten har varit föremål för få undersökningar i Sverige. Det finns bara en större studie, nämligen av Liberg (1981). Den population som han studerade 
var dock inte helt typisk för den genomsnittliga huskatten. Det fanns ett starkt inslag av hankatter som hade en mycket lös anknytning till något hushåll och som skaffade nästan all sin föda själva. Liberg fann dock inga eller bara små skillnader mellan dessa förvildade katter och mera normala huskatter när det gällde deras födoval ute i naturen. De studerade katterna visade sig vara mycket effektiva jägare. De svarade för inte mindre än $18 \%$ av den totala predationen på sork. Denna bedömdes motsvara hela den årliga ungproduktionen bland sorkarna. För hare fann Liberg att $23 \%$ av ungproduktionen konsumerades av katterna. Han bedömde att kattens uttag kunde innebära minskat jaktutbyte för människan under hösten. Däremot kunde han inte avgöra om det påverkade storleken av nästa års harstam. Andra liknande uppgifter kommer från George (1974) som ansåg att katterna var så effektiva sorkpredatorer att de över stora delar av USA orsakade födobrist för rovfåglar.

I denna uppsats skall jag försöka uppskatta hur många fåglar som de svenska katterna tar och diskutera om detta uttag kan ha effekt på de svenska fågelbeståndens storlek. Eftersom det inte finns några svenska studier att bygga på baserar jag uppskattningen på data från en engelsk och en amerikansk studie.

Churcher \& Lawton (1987) genomförde under ett års tid, från sommaren 1981 till sommaren 1982, en undersökning av hur många djur katterna i den engelska byn Felmersham fångade. Det fanns under året i genomsnitt 70 katter i byn. Varje kattägare fick numrerade plastpåsar i vilka alla byten eller rester av byten som katterna drog hem placerades. Påsarna samlades in regelbundet och bytena artbestämdes. Totalt registrerade man 1090 byten, d.v.s. ca 15 byten per katt. Ungefär 36\% av bytena var fåglar, d.v.s. 5,5 per katt och år. Gråsparv dominerade (16\%) och övriga arter var främst typiska trädgårdsfåglar såsom taltrast, koltrast och rödhake.

I en amerikansk undersökning fann George (1974) att huskatter bara drar hem ungefär hälften av de byten de fångar. Om denna siffra var giltig även för katterna i Felmersham skulle den årliga predationen per katt ha uppgått till ca 30 djur, varav ca 11 fåglar.

Hur många katter finns det i Sverige? Jag har gjort en uppskattning baserad på förhållandet i England. Enligt UFAW (1981) finns i England ungefär en katt per fyra hushåll. Om förhållandet är detsamma i Sverige skulle antalet katter vara drygt 900.000, eftersom antalet hushåll är ungefär 3,7 miljoner (Statistisk årsbok 1989). På förfrågan från mig har Olof Liberg, utan att känna till denna beräkning, uppskattat antalet katter i Sverige till ungefär en miljon. De två värdena är så samstämmiga att jag använder dem. Den totala kattpredationen på fågel skulle således i Sverige vara ungefär 10 miljoner fåglar, förutsatt att den svenska medelkatten också tar ca 11 fåglar om året. I en lista på sid. 7 i Bradshaw (1992) finns antalet katter i många olika länder angivet, dock ej för Sverige. För Finland anges 0,104 och för Danmark 0,303 katter per innevånare. Om Sveriges kattbestånd stämmer med det finska, är antalet katter i Sverige just det jag nyss beräknat. Om det däremot är mera likt det danska, skulle antalet katter i Sverige vara ungefär 2,5 miljoner och därmed predationen väsentligt högre än 10 miljoner fåglar. Jag använder dock här den lägre siffran för att inte riskera att överskatta kattens betydelse.

Vilken effekt har då detta på fågelfaunan? Ulfstrand \& Högstedt (1976) uppskattade att det fanns ungefär 95 miljoner fågelpar i landet. Jag har gjort en uppskattning baserad på täthetsvärden från olika inventerade provytor och kommit till nästan samma siffra, 85 miljoner par. Det bör finnas en ganska stor andel icke häckande fåglar, varför man torde kunna räkna med att det före häckningen finns ungefär 200 miljoner fågelindivider i landet. En rimlig uppskattning av deras ungproduktion skulle kunna vara 1,5 flygga ungar per individ. Efter häckningen skulle det i så fall finnas ungefär 500 miljoner fåglar. Majoriteten av dem är småfåglar och alltså potentiella byten för katten.

Eftersom vi vet att fåglarnas antal är ungefär detsamma år från år, kan vi dra slutsatsen att ungefär 300 miljoner fåglar dör av olika orsaker under loppet av ett år. Katterna skulle således svara för bara ca 3\% av dödligheten. Att andelen blir så låg när man räknar på totala fågelbeståndet är inte överraskande med tanke på att de flesta fåglar häckar i skogar och andra biotoper där det bor få männskor och där det därför också finns få katter. Det intressanta är vilken inverkan katterna har på fågelfaunan i tätorterna och i närheten av annan bebyggelse där tätheten av katter är stor.

Något säkert svar på denna fråga kan inte ges eftersom det saknas goda data på antalet fåglar separat för bebyggda områden med katter. Churcher \& Lawton (1978) försökte uppskatta predationseffekten för en art, gråsparven. Det fanns i Felmersham 340 gråsparvar i april innan häckningen började. Med hjälp av litteraturdata (Summers-Smith 1963) uppskattade Churcher \& Lawton att beståndet efter häckningen uppgick till ca 700 fåglar. Katterna tog med säkerhet 130 sparvar. Sannolikt var ca 15\% av de oidentifierade bytena också sparvar, totalt 170 
sparvar. Om katterna bara tog hem hälften av vad de dödade kan så många som ca 350 sparvar ha tagits, d.v.s. hela föryngringen. Det är därför sannolikt att kattpredationen hade en reell effekt på beståndsstorleken, d.v.s. att det skulle ha funnits fler häckande gråsparvar i byn om det inte funnits några katter.

En indikation i samma riktning utgör det faktum att man i undersökningen fann ett tydligt negativt samband mellan antalet byten per katt och tätheten av katter i olika delar av byn. Ett tätt kattbestånd skulle alltså ha sänkt bytesförekomsten så mycket att katterna fick svårare att fånga ytterligare fåglar. Men eftersom det saknas kontrollvärden kan man inte utesluta möjligheten att skillnaden i stället berodde på att det i de kattäta delarna också var ogynnsamt för sparvar ur andra synpunkter.

Det ligger nära till hands att överföra resultaten från gråsparvarna till övriga fågelarter. Slutsatsen skulle bli att katter verkligen kan utgöra en faktor som lokalt minskar antalet fåglar. Den höga predationen på gråsparvarna, som ju häckar någorlunda skyddat från katter, visar att en säker häckningsplats inte innebär skydd mot kattpredationen. Många arter söker liksom sparvarna sin föda på marken, t.ex. trastar, rödhakar och starar, och är där exponerade för katternas jakt. Staren, trots att den häckar i håligheter, var det vanligaste fågelbytet i Libergs (1981) undersökning.

Huruvida resultaten från Churcher \& Lawton's (1987) engelska och George's (1974) amerikanska studier kan överföras till att gälla också Sveriges katter kan diskuteras. Det finns dock inget som tyder på att svenska katter skulle bete sig annorlunda. Uppskattningen av antalet katter i Sverige är något osäker och det finns ingen säker kunskap om hur stor andel av Sveriges katter som har friheten att gå ut och jaga själva. Jag har helt enkelt antagit att det stora flertalet svenska katter är normala huskatter som vistas mycket utomhus.

I en senare amerikansk studie har Mitchell \& Beck (1992) försökt uppskatta kattpredationen i Virginia. Det rörde sig om ett litet stickprov, bara fem katter under sammanlagt 28 månader. De drog hem i medeltal 7 fåglar per katt och år. Om man liksom ovan räknar med att de i verkligheten dödat dubbelt så många byten låg deras predation på 14 fåglar per katt och år, en siffra som är mycket lik den i Felmersham. I Nordamerika finns ca 60 miljoner katter (Springston 1991, citerad i Michell \& Beck 1992), vilket innebär att huskatterna i Nordamerika dödar minst 800 miljoner fåglar per år.

Vad är det som skulle kunna göra just katten till en svår predator i jämförelse med andra fågeljägare såsom sparvhök och sparvuggla? Det är det enkla faktum att den får en stor del av maten i hushållen. Under vintern är detta grunden för överlevnad. Om alla människor skulle stänga dörren för katterna skulle de mycket snabbt dö ut eller reduceras till de låga nivåer som är typiska för vilda rovdjur. Den höga predationen från katterna upprätthålls således av människans stödutfodring.

Man skulle kunna tro att huskatter som får mat från hushållen inte skulle ägna sig åt någon jakt på vilda djur. Här visar olika kattstudier, bl.a. de som anförts ovan, entydigt att även välnärda huskatter som har ständig tillgång på mat hemma ändå bedriver jakt på fåglar och andra djur när de släpps ut. Men katterna är mycket olika som individer. Det finns en del riktiga rekordkatter. Efter det att Churcher \& Lawton (1987) hade publicerat sin studie fick de åtskilliga brev från stolta kattägare som berättade om katter som på ett år kommit hem med flera hundra fåglar. Rekordet innehas i dag av en katt från Dorset som under ett år bar hem över 400 byten (Churcher \& Lawton 1989)! Finns det någon svensk katt som slår det?

Mina beräkningar pekar på att huskattens predation på fåglar är marginell om man ser till hela den svenska faunan. Däremot tyder de på att den i tätorter och kring gårdar kan vara så stor att den påverkar fåglarnas antal. "The delightful, well-fed, domestic cat may be the major killer of small birds and mammals in urban and suburban environments" (Churcher \& Lawton 1989).

Avslutningsvis är det värt att nämna den tanke som Mead (1982) framför i sin analys av kattpredationen på ringmärkta fåglar. Han betonar att den mänskliga bebyggelsens fåglar levt tillsammans med katter i århundraden. De arter som inte klarar kattpredationen finns inte längre kvar utan bara de som lyckats utveckla ett beteende som ger tillräckligt skydd. Man kan alltså fråga sig: Hur skulle tätorternas fågelfauna vara sammansatt om kattens predation eliminerades? Det vore angeläget med några verkligt goda svenska studier av kattpredationen ur bytesdjurens synvinkel!

\section{Referenser}

Churcher, P. B. \& Lawton, J. H. 1987. Predation by domestic cats in an English village. J. Zool., Lond. 212:439-455.

Churcher, P. B. \& Lawton, J. H. 1989. Beware of Well-fed Felines. Natural History, No. 7:40-47.

Bradshaw, J. W. S. 1992. The behaviour of the domestic cat. C. A. B. International, Wallingford, Oxon.

Fitzgerald, B. M. 1988. Diet of domestic cats and their impact on prey populations. Sid. 123-147 i The domestic cat: the 
biology of its behaviour (Turner \& Bateson, eds.). Cambridge Univ. Press, Cambridge.

George, W. G. 1974. Domestic cats as predators and factors in winter shortages of raptor prey. Wilson Bull. 86:384-396.

Liberg, O. 1981. Predation and social behaviour in a population of domestic cat. An evolutionary perspecitive. Doktorsavhandling, Lunds universitet, Lund.

Mead, C. J. 1982. Ringed birds killed by cats. Mammals Review 12:183-186.

Michell, J. C. \& Beck, R. A. 1992. Free-Ranging Domestic Cat Predation on Native Vertebrates in Rural and Urban Virginia. Virginia Journal of Science 43:197-207.

Springston, R. 1991. Killer cats threatening Va. Wildlife. Richmond News-Leader. June 13, Section B.

Statistisk årsbok för Sverige 1989. (Statistical Abstracts for Sweden 1989.) Statistiska Centralbyrån, Stockholm.

Summers-Smith, J. D. 1963. The house sparrow. Collins, London.

Turner, C. D. \& Bateson, P. (eds.) 1988. The domestic cat: the biology of its behaviour. Cambridge Univ. Press, Cambridge.

Turner, C. D. \& Meister, O. 1988. Hunting behaviour of the domestic cat. Sid. 111-121 i The domestic cat: the biology of its behaviour (Turner \& Bateson, eds.). Cambridge Univ. Press, Cambridge.

UFAW. 1981. The ecology and control of feral cats. Potters Bar, Herts: Universities' Federation for Animal Welfare.

Ulfstrand, S. \& Högstedt, G. 1976. Hur många fåglar häckar i Sverige? Anser 15:1-32.

\section{Summary}

\section{Predation on birds by the domestic cat in Sweden}

I have used the estimates of cat predation on birds in the British village of Felmersham (Churcher \& Lawton 1987) to calculate the predation by the domestic cat in Sweden. The Felmersham cats brought home on average 5.5 birds during the year of study. Information given by George (1974) shows that cats bring home about half of their kill, which means that an average cat kills about 11 birds annually. The number of cats in Sweden has been estimated at almost one million. Hence the domestic cats may kill about ten million birds annually in Sweden.

There are about 200 million birds in Sweden at the start of the breeding season (Ulfstand \& Högstedt 1976). With an estimated production of about 1.5 fledged young per bird, there ought to be about 500 million birds at the end of the breeding season. Since the number of birds does not fluctuate much from year to year, about 300 million birds die of different reasons annually. Hence the cat predation in Sweden amounts to only $3 \%$ of the total mortality. This low figure depends on the fact that most birds breed in areas where there are no or few cats. The predation impact in urban and suburban areas and in villages and farms in rural areas must be much higher. However, the proportion of birds that breed in such areas is not known, so it is not possible to estimate the predation there.

Churcher \& Lawton (1987) found that cat predation was about equal to the annual production of young birds in the village, and George (1974) assumed that cat predation could be so high that it caused food shortage for raptors. Liberg (1981) estimated the cat predation on voles to be equal to the annual recruitment and on hares to affect autumn hunting bag. In summary there seems to be general agreement that the domestic cat may have a substantial impact on its prey populations, possibly strong enough to supress breeding population size.

Sören Svensson, Department of Ecology, Ecology Building, S-223 62 Lund, Sweden.

\section{Häckniingsmedlhjäälp hos svart rödstjärrt Phoenicurus ochruros}

\section{REINO ANDERSSON}

I samband med häckningsbiologiska studier av en färgringmärkt population av svart rödstjärt konstaterades 1991 förekomst av s.k. häckningsmedhjälp (då fler individer än det traditionella paret deltar i uppfödningen av ungar). Bland 95 systematiskt bokförda kullar (78 par) i Göteborgs och Varbergs hamnoch industrimiljöer registrerades fyra fall där utomstående hannar hjälpte till med matningen av ungarna. Observationer gjordes både under botiden och flyggperioden och omfattade ettåriga och adulta såväl som oparade och häckande hannar.

\section{Observationer av hjälpmatning}

Hanne A, en helt utfärgad 3K-fågel, uppträdde 1991 som oparad i sitt revir. I grannreviret lämnade fem ungar boet den 29 maj, efter att ha matats hela botiden av en adult polygam hanne och en $2 \mathrm{~K}$-hona. Två dagar senare minskade plötsligt hanne A:s sångintensitet drastiskt, och han visade istället ett märkbart intresse för grannrevirets ungar som tiggde ljudligt av föräldraparet. Den 6 och 9 juni iakttogs A vid upprepade tillfällen mata två speciella ungar tillsammans med honan. Den polygama revirinne- 